\title{
ЭТИКА
}

А. В. ПРОКОФЬЕВ

\section{СТЫД И КОЛЛЕКТИВНО РАЗДЕЛЯЕМАЯ МОРАЛЬНАЯ ОТВЕТСТВЕННОСТЬ *}

В статье подвергнут анализу вопрос о том, какая из негативных эмоций самооченки (стыд или вина) лучше подходит в качестве средства выражения идеи коллективно разделяемой моральной ответственности. Под коллективно разделяемой моральной ответственностью понимают ответственность каждого члена коллектива, объединенного общей идентичностью, за моральные нарушения и злодеяния, совершенные членами этого коллектива, действующими от его имени, в его интересах или в порядке воплощения тех ценностных установок, которые широко разделяются в коллективе. В соответствии с позицией Л. Мэя и ряда развивающих его конщепџию исследователей те члены коллектива, которые не участвовали в нарушении или злодеянии, имеют основания для переживания негативных эмочий самооченки, при условии, что они: а) сохраняют опасные убеждения; б) способствуют сохранению морального климата, который облегчает совершение нарушений и злодеяний; в) не пытаются изменить этот климат; г) сохраняют идентификацию с коллективом, несмотря на злодеяния и нарушения. В политической риторике и этических исследованиях присутствует тезис, что стыд является наилучшим средством выражения коллективно разделяемой ответственности. Л. Мэй рассматривает его как оптимальный коррелят ослабленных, неполных форм ответственности, значит, ответственности всех тех, кто не является непосредственным нарушителем или злодеем. Против этого утверждения выдвинуты два возражения: а) концептуальное, утверждающее структурное несоответствие стыла неполным формам моральной ответственности (К. Стриблен); б) практическое, утверждающее, что стыл не может играть отведенную ему Л. Мэем положительную сочиально-политическую роль (Т. Оукберг). Автор статьи

\footnotetext{
* Статья подготовлена при поддержке Российского фонда фундаментальных исследований, проект 16-03-50063 «Роль стыда в моральном опыте: история проблемы и современные подходы к ее разрешению».
}

Философия и общество, № 32018 40-58

DOI: $10.30884 / j f i o / 2018.03 .03$ 
отклоняет практическое возражение, а на основе анализа концептуального приходит к выводу, что в больиинстве практических контекстов стылд и вина являются вполне обоснованными и дополняющими друг друга средствами выражения коллективно разделяемой ответственности.

Ключевые слова: этика, мораль, моральная ответственность, коллективы с общей идентичностью, стьд, вина, Л. Мэй.

The paper deals with a question: What is the best emotional expression of a shared moral responsibility - guilt or shame? The shared moral responsibility is a responsibility of every member of a group with common identity for moral transgressions committed by some its members acting on the part of the group, for the sake of the group or on the basis of beliefs widely held in the group. Larry May and his adherents maintain that members of an identity group who do not take part in such transgressions are expected to feel negative emotions of self-assessment if they a) retain dangerous beliefs, b) contribute to a moral climate that enables transgressions, c) do not make efforts to change this climate, and d) retain identification with the group. The idea that shame is the best emotional expression of shared moral responsibility can be found both in ethical theory and political rhetoric. For May it is an optimal correlate of all weak and incomplete forms of moral responsibility. So it perfectly suits almost all responsible persons who are not immediate transgressors. There are two main objections to this opinion: conceptual (Cassy Striblen) and practical (Timothy Oakberg). The author argues against the practical objection and relying on the results of the analysis of its conceptual counterpart concludes that in the majority of practical contexts shame and guilt turn out to be completely justified and complementary emotional expressions of shared moral responsibility.

Keywords: ethics, morality, moral responsibility, identity groups, shame, guilt, L. May.

Реализация моральных ценностей в индивидуальной и коллективной практике опирается на различные механизмы, среди которых существенную, хотя и не решающую роль играет осуждение, направленное на нарушителей принципов и норм морали. Имеется в виду как внешнее осуждение, высказанное сторонними наблюдателями или жертвами нарушения, так и эмоционально нагруженное самоосуждение самого нарушителя. Такое самоосуждение сопровождается болезненными негативными эмоциями самооценки, центральное место среди которых занимают вина и стыд. Попытки теоретиков обнаружить разницу между этими эмоциями вращают- 
ся вокруг двух свойств. Первое - зависимость или независимость негативных переживаний от оценок или просто присутствия осведомленной о нарушении реальной или воображаемой аудитории. Стыд часто рассматривается в качестве эмоции, всегда сохраняющей такую связь, вина - в качестве эмоции, которая может возникать и без взгляда другого. Второе свойство - сосредоточенность негативных переживаний на самом нарушении и его морально неприемлемых последствиях или на проявившемся в нарушении качестве морального характера нарушителя. Стыд, по мнению ряда исследователей, фокусирует внимание нарушителя на его собственной личности, вина же заставляет его обращать внимание на произведенный в окружающем мире эффект и заботиться о его преодолении. Я уверен, что есть серьезные обстоятельства, подталкивающие к тому, чтобы рассматривать в качестве релевантных оба разграничения [см.: Прокофьев 2017].

Именно с таким двухфокусным пониманием вины и стыда я хотел бы обратиться к проблеме моральной ответственности за коллективную деятельность и рассмотреть вопрос о том, какая из этих эмоций лучше подходит в качестве средства выражения идеи коллективной моральной ответственности. Неоднородность феномена коллективной ответственности заставляет обсуждать этот вопрос на двух уровнях: уровне коллективной ответственности per se (ответственности организованных коллективов) и уровне заместительной или коллективно разделяемой ответственности (ответственности отдельных членов коллектива за деятельность коллективного целого). В данной статье я буду касаться лишь второго из них.

\section{Коллективно разделяемая ответственность}

Типичная для коллективно разделяемой ответственности ситуация - это случай причинения незаслуженного вреда членами коллектива, которые действуют от его имени, в его интересах или в порядке воплощения ценностных установок, широко разделяемых коллективом. Коллектив, о котором идет речь, может иметь организованные структуры, превращающие его самого в подобие самостоятельного морального деятеля, или не иметь их. Этот аспект не безразличен для коллективно разделяемой ответственности, но не является ее обязательным условием. Таким условием служит 
наличие общей идентичности, которую задают история коллектива и система коллективно разделяемых ценностей. Коллективами, определяющимися общей идентичностью, являются нации и этнические группы, религиозные конфессии, профессиональные сообщества, группы людей, занимающихся одной и той же непрофессиональной деятельностью, и т. д. В дальнейшем для обозначения этой типичной ситуации будут использоваться словосочетания «коллективное нарушение» и «коллективное злодеяние».

Когда члены коллектива, не участвовавшие непосредственно в таких злодеяниях и нарушениях, узнают о них, то перед ними встает вопрос о том, являются ли эти действия поводом для обоснованного самоосуждения и соответственно для переживания вины или стыда. С точки зрения строго индивидуалистической морали самоосуждение здесь неуместно. Единственной оправданной реакцией является негодование, но никак не вина или стыд. Однако в современной этике была выдвинута аргументация, оспаривающая этот тезис. Она черпает ресурсы из опыта обсуждения вопроса об ответственности немцев за злодеяния нацистского режима, но в целостном виде была представлена в трудах американского философа Лэрри Мэя. С точки зрения Мэя, индивидуалистический образ морали не отражает многообразия связей между индивидуальной и коллективной практикой, а также морального значения этих связей. Обоснованность самоосуждения членов коллектива, не принимавших непосредственного участия в коллективных злодеяниях и нарушениях, определяется, по Мэю, следующими факторами.

Во-первых, она связана с тем, что формирование и сохранение морально неприемлемых, опасных убеждений (расистских, сексистских, являющихся основой для дискриминации по религиозному или этническому признаку) являются небрежностью, создающей риск причинения вреда другим людям. Если член коллектива, в котором подобные ценностные установки не просто распространены, но и глубоко интегрированы в коллективную идентичность, не пытается перестроить свою систему нормативных ориентиров, используя для этого возникающие время от времени ситуации, в которых активизируется его спонтанная моральная чувствительность, то он становится похож на человека, который целится в соседа из пистолета и не убивает только потому, что в его пистолете случайно не оказа- 
лось патронов. Убежденный расист не участвует в преступлениях на расовой почве только потому, что ему повезло и он не оказался в нужное время в нужном месте. Поэтому он несет ответственность за каждое злодеяние, совершенное на основе системы ценностей, которую он разделяет. Она не равна ответственности непосредственных злодеев, но тем не менее существенна. Естественно, что в этом случае речь идет не о смутных и абстрактных убеждениях, а об убеждениях, превратившихся в устойчивый мотив - в действенную практическую установку [Мау 1992: 49-50].

Во-вторых, сохранение морально неприемлемых и опасных убеждений вносит свой вклад в формирование климата, или атмосферы, сообщества. Этот климат складывается за счет многочисленных единичных суждений его членов о том, что является морально допустимым и недопустимым. Каждое единичное суждение достраивает тот микро- и макросоциальный контекст, в котором вредящие действия оказываются одобряемыми, терпимыми либо, напротив, встречают повсеместное противодействие. В расистском или сексистском климате существует гораздо большая вероятность причинения расистски или сексистски мотивированного вреда, поэтому те, кто способствует его формированию, соучаствуют не просто в создании климата, а в совершении конкретных злодеяний. Мэй использует метафору «первой соломинки»: для того, чтобы последняя соломинка переломила спину верблюда, должны быть многочисленные предыдущие, включая первую. Они лишь по видимости не являются причиной катастрофы [Ibid.: 48]. Неблагоприятный климат формируют не только те члены коллектива, которые имеют опасные практические установки, но и те, чьи убеждения не обладают достаточной силой, чтобы мотивировать их поступки, и даже те, кто имеет не оформившиеся убеждения, а всего лишь полуосознанные предубеждения расистского или сексистского типа. Все они оказываются ответственными за коллективные злодеяния и нарушения.

В-третьих, бездействием, которое увеличивает вероятность коллективных злодеяний и нарушений, является не только сохранение опасных убеждений, но и неучастие в изменении климата сообщества. Это обстоятельство касается тех его членов, которые, не имея опасных убеждений, не оказывают им противодействия, 
не предпринимают попыток объединить людей, понимающих, что какие-то общепринятые практики и широко разделяемые в коллективе ценности сомнительны в моральном отношении. Конечно, для успеха в деле изменения морального климата нужна кооперация множества людей, и нет никаких гарантий, что она возникнет в действительности. Однако каждый, кто не сделал хотя бы каких-то шагов для ее инициации, способствует формированию контекста, в котором члены его группы превращаются в нарушителей или злодеев [Мау 1992: 105-126].

В-четвертых, самоосуждение членов коллектива в случае коллективных злодеяний и нарушений оказывается обоснованным в силу сохранения ими идентификации с группой, причисления себя к коллективному «мы». Такое отношение к коллективу может возникать на основе тех его особенностей, которые никак не связаны с нарушениями и злодеяниями и могут вызвать гордость даже у самого придирчивого морального ригориста. В этой связи складывается вполне обоснованная симметрия позитивных и негативных моральных эмоций. Гордость за достижения своего коллектива, отношение к ним как к «нашим» или «своим» неизбежно сопровождаются негативными эмоциями самооценки, порожденными моральными сбоями в его жизни [Ibid.: 154]. Член коллектива, признающий факт нарушений и злодеяний, совершенных другими его членами от имени и во имя коллективного целого, неизбежно дистанцируется от него. В этом состоит его моральный долг. Однако такое дистанцирование редко приобретает форму полного разрыва; оно заставляет переосмыслить принадлежность к коллективу, но не разрушает идентификацию с ним [Ibid.: 160].

В прошедшие после работы Мэя четверть века теория коллективно разделяемой ответственности обогатилась двумя интересными дополнениями, заслуживающими специального упоминания. Грегори Меллема ввел в нее понятие «квалифицирующее действие» [Mellema 1997: 12]. Оно удачно формализует связь индивидуальной деятельности и ответственности индивидов за коллективные злодеяния. Таким действием может быть и сохранение опасных убеждений, и бездействие в отношении морального климата своей группы, и отсутствие полного дистанцирования от нее. Конечно, можно представить себе случаи, когда полное дистанциро- 
вание от коллектива невозможно. Это демонстрирует определенную ограниченность понятия квалифицирующего действия, его неспособность охватить все случаи коллективно разделяемой ответственности. Но тем не менее оно очень важно для приведения в систему некоторых не самых упорядоченных рассуждений Мэя.

Кэсси Стриблен посчитала необходимым уточнить механизмы индивидуального влияния на климат сообщества. Она предложила развернутое пояснение к рассуждению Мэя о роли бездействия и небрежности в генезисе коллективно разделяемой ответственности. Для этого она обратилась к нарративной теории идентичности, утверждающей, что индивидуальная идентичность формируется на основе создания человеком повествований о своей прошлой жизни и проекции этих повествований в будущее в виде предпочтений и планов. В процессе создания нарратива деятель отбирает факты своей биографии, связывает их между собой, придает им смысл, конструируя тем самым сложносоставной ответ на вопрос о том, кто он такой. Индивидуальные нарративы формируются на основе и на фоне групповых, но при этом, вплетаясь в групповые нарративы, способны их в той или иной степени изменять. Этически значимым выражением коллективных нарративов, то есть таким, которое непосредственно связано с характером совершаемых поступков, являются коллективные нормы. Соответственно, каждый член коллектива, создавая и пересказывая другим свой нарратив, поддерживает или, наоборот, разрушает доминирующие в коллективе нормы поведения. Если эти нормы имеют моральные изъяны, то член коллектива, сознательно или бессознательно поддерживающий их на нарративном уровне, оказывается ответственным за все поступки других членов коллектива, которые являются исполнением норм [Striblen 2014: 123-159].

Коллективная вина или коллективный стыд? (Австралийский кейс)

До сих пор обсуждение проблемы коллективно разделяемой ответственности велось мной без учета различий между ее эмоциональными коррелятами. В своей реконструкции подходов к выявлению ее оснований я пользовался единым рядом негативных эмоций самооценки, в который входили как вина, так и стыд. Однако, 
принимая во внимание возможность того, что у каждого из этих переживаний могут быть собственные, эксклюзивные практические контексты, вполне оправданно задаться вопросом о том, как соотносится коллективно разделяемая ответственность с виной и стыдом. Этот вопрос не является сугубо академическим. Риторические призывы к коллективам, не признающим свою моральную ответственность, а также реальный опыт коллективно разделяемой ответственности могут быть сосредоточены как на понятии «стыд», так и на понятии «вина». В некоторых политических сообществах даже разгорается дискуссия о том, какое переживание было бы более уместным для их членов.

Хорошим примером таких споров являются дискуссии 19902000-х гг. по поводу ущерба, причиненного аборигенному населению Австралии, в особенности детям, насильственно разлученным со своими семьями (так называемые «украденные дети» или «украденное поколение»). Один из аспектов данных дискуссий состоял именно в том, что должны чувствовать современные белые австралийцы по поводу этих событий. Австралийские консерваторы, возглавляемые премьер-министром Джоном Ховардом, настаивали на том, что в этом контексте уместны глубокие сожаления, не выражающие «межпоколенческой моральной ответственности». Их аргументация была тесно связана с невозможностью обосновать нравственное требование, в соответствии с которым дети должны чувствовать вину за грехи своих отцов: «От австралийцев нынешнего поколения нельзя требовать, чтобы они приняли на себя вину и осуждение за совершенные в прошлом действия и за существовавший в прошлом политический курс, которые они никак не могли контролировать» [The Transcript... 1997].

Критики этой позиции полагали, что отношение современных австралийцев к совершенному их отцами должно преломляться именно через призму коллективно разделяемой межпоколенческой моральной ответственности. С их точки зрения, подлинное национальное примирение было бы невозможно без принесения публичного извинения коренным австралийцам. Одновременно критики Ховарда выступали против исчерпывающего характера предложенной им альтернативы: или признание вины, или дистанцированное сожаление о страданиях, постигших аборигенов. Адекват- 
ной реакцией на прошлые злодеяния своего политического сообщества, по их мнению, должна быть не вина, а стыд - стыд не столько за отдельные акты нарушения прав человека, сколько за общее состояние своей нации, которое позволило им реализоваться на практике. Большая группа австралийских интеллектуалов упорно отстаивала эту позицию, в итоге последняя легла в основу нескольких ключевых публичных документов, связанных с процессом примирения. К примеру, в поворотном судебном решении о земельных правах аборигенов 1992 г. говорилось, что лишение аборигенного населения земель являлось «самым темным аспектом национальной истории», «оно оставило нации наследие неописуемого стыда», «нация как целое будет оставаться униженной, пока она не признает совершенную в прошлом несправедливость и не отступится от нее» [Mabo... 1992]. Премьер-министр Пол Китинг в речи того же года, подчеркнув, что вина является «неконструктивным чувством», тем не менее связал убийства, лишение земель, дискриминацию и эксклюзию с коллективным «мы» австралийцев и указал на то, «что, совершая все это, мы не видели того, что этим позорим себя» [Australian... 1992]. Наконец, в знаменитом заявлении премьер-министра Кевина Радда 2008 г., которое поставило точку в спорах о необходимости извинения перед коренными жителями, дискриминация в их отношении была названа «величайшим пятном на душе нации», что также коррелирует со спецификой переживания стыда [Apology... 2008; более подробную реконструкцию дискуссии см.: Muldoon 2017].

\section{Коллективная вина или коллективный стыд?} (Контуры теоретической дискуссии)

В социальной этике последних десятилетий обсуждение разных способов выражения коллективно разделяемой ответственности на уровне эмоций было инициировано Л. Мэем. Он попытался с помощью обращения к специфике различных эмоций самооценки решить важнейшую проблему теории коллективной ответственности - проблему конструктивного разграничения ответственности, связанной с собственными поступками деятеля и с поступками других членов его коллектива. Еще Ханна Арендт в работе «Коллективная ответственность» выразила опасение, что там, где ви- 
новны все, на деле не будет виновен никто [Арендт 2003: 205]. Мэй предположил, что это затруднение можно преодолеть за счет понимания моральной ответственности как явления, которое имеет разную интенсивность и разные формы эмоционального выражения. Опасения, подобные опасению Арендт, по его мнению, возникают лишь тогда, когда теоретики искусственно обедняют «ландшафт» моральной ответственности. В этом «ландшафте», формирующемся за счет разных форм «полной» и «неполной» ответственности, Мэй выделяет целый спектр переживаний: вину, стыд, раскаяние, моральное сожаление, чувство моральной запятнанности. Они представляют собой континуум, в котором вина занимает крайнее положение. Она связана с наиболее интенсивным осуждением людей и их поступков. Другие формы выражения ответственности обладают гораздо меньшим осуждающим «зарядом» [Mау 1992: 10, 16, 34-35].

Л. Мэй не предлагает строгой схемы распределения эмоций, связанных с самоосуждением, между типичными случаями индивидуальной и коллективно разделяемой ответственности. Однако его позицию по этому вопросу можно реконструировать на основе анализа словоупотребления и решения частных теоретических проблем. Для непосредственных участников злодеяний обоснованным выражением ответственности, по Мэю, является чувство вины, при этом окружающие могут осуждать их, то есть указывать им на их виновность. В отношении людей, сохраняющих опасные, противоречащие нравственным ценностям практические установки, которые могут в любой момент «выстрелить» насилием или дискриминацией, Мэй ведет речь об обоснованности чувства вины, не сопровождающегося возможностью внешнего осуждения. Параллельно он упоминает в этом контексте и стыд [Ibid.: 50-51]. Случаи, связанные с неспособностью членов коллектива изменить его моральный климат через преобразование собственных убеждений или через влияние на убеждения других, относятся, по Мэю, к случаям коллективного бездействия. Здесь уместен именно стыд, а не вина, как в силу того, что в нем заложена меньшая интенсивность осуждения, так и в силу того, что он имеет приоритетную связь с моральным качеством личности [Ibid.: 109, 120-121]. Наконец, 
Мэй выделяет те случаи, в которых бездействие члена коллектива не влияет на вероятность совершения коллективных нарушений и злодеяний. Они включают в себя часть случаев сохранения опасных убеждений, часть случаев отказа от противодействия их распространению и все случаи, когда ответственность связана с произвольным сохранением идентификации индивида с коллективом. Это, по мнению Мэя, сфера знаменитой Ясперсовой «метафизической вины» [Ясперс 1999: 59-60]. Однако, в отличие от Ясперса, Мэй полагает, что у метафизической вины есть свои моральные соответствия. Центральным соответствием является ощущение моральной запятнанности, но наряду с ним у Мэя фигурирует и стыд [Мау 1992: 154-155]. Среди причин, по которым здесь неуместна вина, Мэй упоминает не только отсутствие способности деятеля что-либо изменить, но и отсутствие простого и прозрачного поведенческого выбора, к которому всегда бывает привязана вина [Ibid.: 150].

Попытка Л. Мэя отождествить со стыдом значительную (а по сути - преобладающую) часть переживаний, выражающих коллективно разделяемую моральную ответственность, сталкивается с довольно жесткой критикой. Она имеет два основных направления. Одно касается концептуальной точности предложения Мэя, второе - его практической приемлемости. Вопрос о концептуальной точности остро поставила К. Стриблен. Она обратила внимание на то, что для Мэя при обсуждении всех форм и проявлений коллективно разделяемой ответственности ключевым моментом является индивидуальное «участие» в совершившемся злодеянии, пусть в очень разных, подчас непрямых и сложно опосредствованных, проявлениях. Используя терминологию Г. Меллемы, отсутствующую в работах Стриблен, можно было бы сказать, что Мэй во всех случаях ищет какой-то, хотя бы самый неявный и рудиментарный, квалифицирующий акт. Сохранение опасных установок, бездействие в отношении возможностей изменения морального климата коллектива, игнорирование возможностей дистанцироваться от злодеяния или от коллектива в целом - все это, по мнению Стриблен, есть различные формы участия в злодеянии и даже вклада в него. То понимание вины, которое использует Мэй, также сосредоточено 
на участии, и значит, вполне логично было бы все случаи коллективно разделяемой ответственности рассматривать как повод для переживания вины [Striblen 2014: 112-114].

Однако, по мнению К. Стриблен, Л. Мэй идет против логики и существенно ограничивает пространство обоснованного переживания вины в контексте коллективной деятельности. Он утверждает, что вина уместна лишь там, где участие можно рассматривать не просто как вклад в злодеяние, а как вклад, который необходим для возникновения морально неприемлемого результата (незаслуженных унижений, страданий или смертей). Если же вклад не является необходимым, если он избыточен для возникновения этих последствий, то участие превращается в повод для стыда. Это дополнительное ограничение Стриблен считает лишенным весомых оснований. Во-первых, оно не может использоваться в связи с эпистемологическими затруднениями (к примеру, невозможно с высокой степенью достоверности знать, является ли мой вклад в создание климата, способствующего совершению злодеяний, необходимым для того, чтобы они совершались, или же ничего не меняющим) [Ibid.: 109-110]. Во-вторых, это ограничение никак не связано с природой вины и стыда. Вполне логичным и имеющим под собой определенные основания являлся бы тезис: член коллектива, не вносящий необходимого вклада в злодеяние, несет ответственность за сохранение опасных убеждений или за отказ дистанцироваться от группы, но не за само это злодеяние. Этот тезис создает основу для теоретической дискуссии, одна из сторон которой отрицает коллективно разделяемую ответственность как таковую. Однако утверждение, что данный член коллектива несет ответственность за злодеяние, но должен испытывать стыд, а не вину, оснований под собой не имеет и повода для содержательной дискуссии не создает [Ibid.: 112-113]. Другой важной точкой опоры критики К. Стриблен является рассуждение, предложенное Гэбриэль Тэйлор. Если стыд - это результат нарушения норм, которые запрещают не действия определенного рода, а обладание определенного рода личностными свойствами, то это отсутствие связи с действием превращает стыд в переживание, вообще не выражающее моральной ответственности [Taylor 1985: 60-61]. 
«Практическое» направление критики тезиса о стыде как центральном переживании в сфере коллективно разделяемой ответственности опирается на предполагаемую неспособность коллективно разделяемого стыда выполнять ту общественно полезную функцию, которую, по мнению Мэя, он призван выполнять. Как замечает Тимоти Оукберг, «Мэй полагает, что, культивируя стыд, мы можем мотивировать людей к тому, чтобы они совершенствовали самих себя и общество. Однако это предположение не принимает в расчет десятилетия эмпирических исследований, свидетельствующих в пользу антиобщественных последствий предрасположенности к чувству стыда» [Oakberg 2016: 759]. В этой связи Оукберг последовательно воспроизводит несколько положений психологической критики индивидуального стыда как эмоции, которая недостаточно адаптивна и лишена сколько-нибудь значительного просоциального потенциала. Первый пункт в его списке касается тенденции стыдящегося человека к уклонению от общения с другими по поводу тех обстоятельств, которые вызвали стыд, и к сокрытию самих этих обстоятельств.

T. Оукберг акцентирует второй момент, указывая на то, что предвосхищение коллективно разделяемого стыда должно подталкивать членов коллектива к сокрытию нарушений и злодеяний, к замалчиванию или подтасовке фактов, ложащихся пятном на репутацию сообщества [Ibid.: 759-760]. Однако в психологической критике стыда однозначно преобладает первый момент. Уклонение от общения по поводу нарушения, вызвавшего стыд, с точки зрения критиков стыда, тождественно уклонению от попыток восстановить отношения с жертвами нарушения на основе принесения им извинений и компенсации понесенного ими ущерба. А это - ключевые деятельные корреляты ретроспективной моральной ответственности, важнейшие подтверждения искренности связанных с ней переживаний. К. Стриблен, которая, в отличие от Оукберга, не пытается выстроить целостную систему практических контрагрументов против коллективного стыда, ссылается именно на это обстоятельство. Группа, пораженная коллективным стыдом, с ее точки зрения, выступает в качестве очень неудобного партнера по процессу восстановления отношений со своими жертвами [Striblen 2014: 114-115]. 
Второй пункт касается уже не просто тенденции стыдящегося человека скрывать нарушение, а его склонности к переносу ответственности за совершенное на других. Стыд как предельно болезненное чувство, ставящее под вопрос возможность самоуважения (позитивного восприятия собственной личности), порождает крайне жесткие, разрушающие любые моральные сдержки механизмы психологической самозащиты. Одним из них является такая интерпретация собственных моральных нарушений, которая позволяет рассматривать их как справедливый ответ на провокации со стороны других людей [Oakberg 2016: 760-761]. В этой связи другой человек (довольно часто это жертва нарушения) оказывается предметом гневных и негодующих переживаний нарушителя. В этом состоит третий пункт критики Оукберга. Последний ссылается при этом на исследования так называемых «круга стыда и гнева» или «спирали стыда и гнева», которые предполагают взаимное воспроизводство и взаимную эскалацию этих эмоций [Ibid.: 762]. В коллективном контексте стыд, по его мнению, генерирует очень похожие спиралевидные процессы. Наконец (и это четвертый пункт в списке Оукберга), стыд в соединении с гневом является источником агрессивных, насильственных действий. Данный вывод Оукберга опирается на исследования Джеймса Гиллигана, касающиеся подростковых и тюремных субкультур [Ibid.: 763].

\section{Оценка дискуссии о коллективном стыде}

Концептуальное возражение против позиции Л. Мэя мне представляется достаточно сильным, однако выводы, сделанные на его основе К. Стриблен, вызывают серьезные сомнения. Прежде всего невозможно принять тезис Мэя о том, что стыд является идеальным эмоциональным выражением малых степеней интенсивности осуждения (так называемой «неполной моральной ответственности»). В своих наиболее острых выражениях стыд представляет собой очень интенсивную эмоцию самоосуждения, ничем не уступающую по силе вине. Психологическая критика стыда, на которую опирается Т. Оукберг, во многом построена именно на том, что мощный травматический эффект стыда не находит позитивного практического выхода. И если с отсутствием практического выхода можно поспорить, то в травматичности переживания стыда усомниться невозможно. 
Не менее проблематична мысль Л. Мэя о том, что коллективно разделяемая вина есть только там, где присутствует легко идентифицируемое влияние члена коллектива на вероятность наступления морально неприемлемых последствий, а стыд может иметь место и вне этого контекста. Неясно, что именно в природе вины и стыда заставило бы нас принять это утверждение. Поэтому можно согласиться с К. Стриблен в том, что вина должна переживаться во всех случаях, где есть квалифицирующий акт, соединяющий деятельность члена коллектива и совершенное злодеяние. Кстати, Мэй и сам не соблюдает введенное им правило, обсуждая случай опасных практических установок, сохранение которых подобно стрельбе из незаряженного пистолета. Напомню, что их обладатель рассматривается Мэем как кандидат на вполне обоснованное переживание чувства вины. Однако он может оказаться изолированным от своего сообщества. Находясь в этих условиях, он никак не влияет на вероятность совершения коллективных нарушений или злодеяний. Но основания для переживания им вины сохраняются.

Вместе с тем расширение сферы коллективно разделяемой вины, удачно обоснованное Стриблен, совсем не обязательно ведет к отстаиваемому ею же предельному сужению сферы коллективно разделяемого стыда. К. Стриблен утверждает, что вина должна присутствовать там, где имеет место любая форма участия в коллективных нарушениях и злодеяниях, а стыд оказывается уместен лишь в тех случаях, когда связь члена коллектива с нарушением или злодеянием обеспечивается исключительно его идентификацией с коллективом. Аргумент Г. Тэйлор о том, что стыд не связан с конкретным предосудительным действием, поддерживает это ее убеждение. В этой связи становится ясно, что Стриблен исключает возможность параллельного и при этом обоснованного переживания вины и стыда по одному и тому же поводу. Однако с этим трудно согласиться прежде всего потому, что аргумент Тэйлор не выдерживает критики. В значительном количестве случаев стыд является эмоциональной реакцией именно на действие, хотя и переживается не столько в связи с негативными последствиями этого действия для других людей, сколько в связи с тем, что в действии определенным образом раскрылась личность совершившего его человека. Отсюда следует, что перечисляемые Стриблен случаи коллективной ответственности (сохранение опасных установок, 
бездействие в отношении возможностей изменения морального климата коллектива, игнорирование возможностей дистанцироваться от злодеяния или от коллектива в целом) должны вызывать как стыд, так и вину. При этом интенсивность обеих эмоций должна отражать степень непосредственности участия члена коллектива в нарушении или злодеянии.

Как мне представляется, стыд без параллельного переживания вины уместен только в тех случаях, где оказываются невозможны любые формы квалифицирующего акта. А это случаи, в которых коллективно разделяемая ответственность опирается исключительно на общую идентичность и не зависит даже от желания или нежелания члена коллектива дистанцироваться от него. Можно предложить гипотезу, что такова ответственность за прошлые злодеяния коллектива тех его сегодняшних членов, которые предприняли все возможные усилия по дистанцированию как от злодеяний, так и от самого коллектива, однако их попытки разрушить идентификацию с коллективным целым оказались неудачными по объективным, не зависящим от них обстоятельствам. Мне кажется, что это редкая и не самая интересная в практическом отношении ситуация. К примеру, она явно не соответствует разобранному выше кейсу современных австралийцев, которые не разделяют расистских убеждений и активно осуждают прошлую политику своей нации в отношении коренных жителей континента. Ведь дистанцируясь от прошлых злодеяний своего политического сообщества, они совершают выбор в пользу сохранения своей принадлежности к нему. Они гордятся и главное - хотят гордиться всем лучшим, что было в его истории. Значит, коллективно разделяемая вина здесь столь же обоснована, как и коллективно разделяемый стыд. Для того чтобы остались основания только для стыда, нужно представить себе австралийца, который ужаснулся фактам геноцида коренного населения Австралии, совершенного его нацией в прошлом, попытался разорвать свою идентификацию с ней, но так и не смог вытравить из себя черты своей «австралийскости».

Что касается практического возражения, то неспособность стыда сыграть роль эмоции, которая способствует уменьшению количества коллективных нарушений и злодеяний, является очевидным преувеличением, так же как очевидным преувеличением является 
обосновывающая этот вывод негативная оценка роли стыда в сфере индивидуальной моральной практики. Критикуя теоретический проект Л. Мэя, Т. Оукберг опирается на многостроннюю дискредитацию стыда, осуществленную Джун Тэнгни и некоторыми ее соавторами [Tangney, Dearing 2002]. Однако у проекта Тэнгни есть несколько существенных недостатков. Во-первых, он расходится с данными ряда недавних исследований, сформировавших к настоящему моменту обратный, реабилитационный тренд в психологической теории стыда. Их авторы фиксируют существенные просоциальные следствия этой эмоции, которые связаны с попытками восстановления репутации. Стыдящийся человек стремится сделать что-то такое, что могло бы изменить мнение о нем тех людей, которые были свидетелями события или действия, вызвавших у него стыд. Стремление восстановить репутацию является такой тенденцией, которая уравновешивает второе базовое стремление, порождаемое стыдом, - желание уклониться от взаимодействия с другими людьми. Избегание превращается в главное поведенческое следствие стыда лишь в тех случаях, когда: а) восстановление репутации требует очень больших усилий или, учитывая сложившийся коммуникативный контекст, маловероятно; б) у человека имеется не просто способность переживать стыд, а предрасположенность к этому переживанию. Таким образом, негативные следствия стыда, превращающие его в сомнительную в моральном отношении эмоцию, возникают лишь на фоне его болезненной гипертрофии.

Во-вторых, негативное отношение теоретиков к стыду формируется на основе противопоставления стыда и вины, в рамках которого моральные недостатки стыда полагаются на контрастном фоне моральных достоинств вины. При этом не возникает вопрос о возможных недостатках вины, которые могли бы стать контрастным фоном для моральных достоинств стыда. Скажем, психологи установили, что интенсивность и устойчивость чувства вины очень сильно зависит от степени вероятности дальнейшего взаимодействия с жертвой нарушения. Вина дает наилучший просоциальный эффект в условиях прямой взаимности. При ее отсутствии она легко угасает. Стыд, в свою очередь, меньше зависит от вероятности будущего общения с жертвой и поддерживает непрямую взаимность, без которой немыслим моральный опыт [Nelissen et al. 2013: 
361]. Или переживающий вину человек имеет предрасположенность к отрицанию связи предосудительного деяния с негативными чертами его личности. Под влиянием чувства вины индивиды склонны рассматривать нарушение как случайный сбой или как присутствие в себе какого-то чуждого начала, иного Я, на время перехватывающего управление поступками [Taylor 1985: 89-92]. Таким образом, вина заставляет деятеля концентрироваться на симптомах своей «моральной болезни» вместо ее причин и даже более того - способствует отрицанию самого факта заболевания. Образ самого себя, возникающий на основе разрыва связи между действием и личностью деятеля, является искаженным, недостаточно беспристрастным. Он создает плохую основу для самосовершенствования. Стыд же способствует разоблачению этого самообмана. Он дополняет вину, поскольку у гармоничной моральной личности озабоченность последствиями своих действий должна сочетаться с озабоченностью качеством собственного морального характера.

Это рассуждение может быть распространено на коллективную вину и коллективный стыд. Тогда окажется, что коллективная вина служит действенным мотивом для восстановления отношений с пострадавшими и возвращения им морального статуса, попранного предосудительными действиями коллектива, а стыд - мотивом для такой перестройки коллективной идентичности, которая снижает возможность коллективных злодеяний в будущем (некоторые примеры эффективного использования стратегии пристыжения коллективов и их членов см.: [Джекет 2016]).

\section{Лuтература}

Арендт Х. Коллективная ответственность / Х. Арендт // Ответственность и суждение. М. : Изд-во Ин-та Гайдара, 2013. С. 205-217.

Джекет Дж. Зачем нам стыд? Человек vs общество. М. : Альпина нонфикшн, 2016.

Прокофьев А. В. Социализированная и десоциализированная концепции стыда: их специфика и возможности соединения // Философия и общество. 2017. № 2(83). С. 68-86.

Ясперс К. Вопрос о виновности. О политической ответственности Германии. М. : Прогресс, 1999. 
Apology to Australia's Indigenous Peoples House of Representatives Parliament House. Canberra, 2008 [Электронный ресурc]. URL: https://pmtrans cripts.pmc.gov.au/release/transcript-15758 (дата обращения: 20.01.2018).

Australian Launch of the International Year for the World's Indigenous People. Redfern 1992 [Электронный ресурc]. URL: https://pmtranscripts.pmc. gov.au/release/transcript-8765.

Mabo v Queensland (No 2) [1992] HCA 23; (1992) 175 CLR 1. 1992 [Электронный pecypc]. URL: http://www.austlii.edu.au/cgi-bin/sinodisp/ $\mathrm{au} / \mathrm{cases} / \mathrm{cth} / \mathrm{high}$ ct $/ 175 \mathrm{clr} 1 . \mathrm{html}$ ? stem $=0 \&$ synonyms $=0 \&$ query $=$ title $+\% 28+"$ mabo"+\%29 (дата обращения: 20.01.2018). 1992.

May L. Sharing Responsibility. Chicago : University of Chicago Press,

Mellema G. Collective Responsibility. Atlanta : Rodopi, 1997.

Muldoon P. A Reconciliation Most Desirable: Shame, Narcissism, Justice and Apology // International Political Science Review. 2017. Vol. 38(2). Pp. 213-226.

Nelissen R. M. A., Breugelmans S. M., Zeelenberg M. Reappraising the Moral Nature of Emotions in Decision Making: The Case of Shame and Guilt // Social and Personality Psychology Compass. 2013. Vol. 7. No. 6. Pp. 355-365.

Oakberg T. J. There Should Not Be Shame in Sharing Responsibility: An Alternative to May's Social Existentialist Vision // Ethical Theory and Moral Practice. 2016. Vol. 19. No. 3. Pp. 755-772.

Striblen C. Group Responsibility: A Narrative Account. Basingstoke : Palgrave Macmillan, 2014.

Tangney J. P. Dearing R. L. Shame and Guilt. New York : Guilford Press, 2002.

Taylor G. Pride, Shame, and Guilt: Emotions of Self-Assessment. Oxford : Clarendon Press, 1985.

The Transcript of the Prime Minister the Non John Howard MP Opening Address to the Australian Reconciliation Convention. Melbourne, 1997 [Электронный ресурс]. URL: https://pmtranscripts.pmc.gov.au/release/transcript10361 (дата обращения: 20.01.2018). 